\title{
Análise via microscopia óptica de um aço bainítico DIN 18MnCrSiMo6-4 austenitizado e resfriado em diferentes meios
}

\author{
Cristiano José Turra ${ }^{1 *}$ (1) \\ Pedro José de Castro ${ }^{1}$ \\ Antonio Figueiredo Silveira ${ }^{\prime}$ \\ Alexandre da Silva Rocha ${ }^{1}$
}

\section{Resumo}

Aços bainíticos de baixo carbono e baixa liga produzidos por resfriamento contínuo apresentam formidável combinação de resistência mecânica e tenacidade para uma série de aplicações. O ponto chave desta interessante combinação está relacionado à microestrutura multifásica, a qual é influenciada principalmente pela composição química e parâmetros de tratamentos térmicos ou termomecânicos. $\mathrm{O}$ modo e a velocidade de resfriamento são parâmetros essenciais nas transformações microestruturais, e impactam no tipo, proporção e refino da microestrutura, determinando o desempenho do material. O objetivo deste trabalho foi avaliar a influência de diferentes meios de resfriamento sobre a microestrutura do aço bainítico DIN 18MnCrSiMo6-4. Amostras do material na condição de recebimento foram submetidas à austenitização e posteriormente ao resfriamento em água e óleo (têmpera), ao ar (normalização), em forno (recozimento) e em banho aquecido (austêmpera). As amostras tratadas foram caracterizadas por microscopia óptica e medições de dureza Vickers. Os resultados mostraram que o resfriamento em forno favorece a formação de ferrita, reduzindo a dureza do material, enquanto que o resfriamento ao ar não modifica significativamente a microestrutura e dureza. Já o resfriamento em banho isotérmico produz bainita granular e bainita em ripas, aumentando ligeiramente a dureza. Os resfriamentos em água e óleo formam martensita com dureza de 436 e $424 \mathrm{HV}$, respectivamente.

Palavras-chave: Aço bainítico; Bainita; Microestrutura multifásica; Resfriamento.

\section{Optical microscopic analysis of a DIN 18MnCrSiMo6-4 bainitic steel austenitized and quenched with different coolants}

\begin{abstract}
Low carbon and low alloy bainitic steels produced by continuous cooling present a formidable combination of strength and toughness for various applications. The key point of this interesting combination is related to their multiphase microstructure, which is mainly influenced by chemical composition and heat treated or thermomechanical parameters. Cooling conditions and rate are the most predominant factors when regarding microstructural transformation, and impact on the resulting phases, quantity and refinement of microstructure, determining the material performance. This work aims at evaluating the influence of different cooling media over the microstructure of DIN 18MnCrSiMo6-4 steel. Steel samples in as received condition were submitted to austenitizing and subsequently cooled in water, oil (quenching), air (normalizing), in the furnace (annealing), and in heated bath (austempering). The treated samples were analyzed by Optical Microscopy and Vickers microhardness measurements. Results showed that cooling from furnace benefits ferrite formation, reducing the material hardness, while air cooling doesn't change the microstructure and hardness significantly. In addition, cooling in heated bath produces granular bainite and lath-like bainite, slightly hardness increasing. Water and oil cooling forms martensite with hardness 436 and $424 \mathrm{HV}$, respectively.
\end{abstract}

Keywords: Bainitic steel; Bainite; Multiphase microstructure; Cooling.

\footnotetext{
${ }^{1}$ Laboratório de Transformação Mecânica - LdTM, Universidade Federal do Rio Grande do Sul - UFRGS, Porto Alegre, RS, Brasil.

*Autor correspondente: cristiano.turra@ufrgs.br
} 


\section{Introdução}

Os aços bainíticos de baixo carbono vem ilustrando boas perspectivas no ponto de vista das indústrias automotiva e de componentes mecânicos em geral. Vários estudos mostram que é possível obter satisfatoriamente maior tenacidade e resistência mecânica através de microestruturas bainíticas formadas em diferentes condições de resfriamento [1-3], o que tem atraído a atenção da indústria metalomecânica. Estes aços de baixa liga com elementos de liga relativamente baratos, tem composição química ajustada para a formação de bainita em diferentes taxas de resfriamento contínuo, resultando em propriedades mecânicas promissoras. Podem apresentar elementos de liga como: $\mathrm{Mn}, \mathrm{Si}, \mathrm{Cr}, \mathrm{Mo}, \mathrm{B}, \mathrm{Al}, \mathrm{Ni}, \mathrm{V}$, Ti entre outros. O Mn fornece aos aços excelentes combinações de resistência e deformabilidade, apesar de que teores elevados de Mn aumentam a formação de austenita retida, segregações nos contornos de grão e bandeamento ao longo do material, que podem prejudicar as propriedades mecânicas [4]. O Si apresenta baixa solubilidade na cementita e isto retarda a sua formação. O retardo provoca a inexistência ou pouca precipitação de cementita, o que produz uma microestrutura bainítica livre de carbonetos e com maior tenacidade [5]. $\mathrm{O} \mathrm{Al}$ apresenta efeito similar ao $\mathrm{Si}$, de forma que rejeita o carbono da ferrita bainítica, enriquecendo a austenita [6]. O $\mathrm{Cr}$, além de aumentar a resistência mecânica (endurecimento por solução sólida), atua como estabilizador da ferrita. O Mo aumenta a energia de ativação de difusão do carbono, enriquecendo as regiões da austenita e possibilitando um aumento da fração de constituintes martensita-austenita (M/A) nas regiões enriquecidas. O constituinte (M/A) é formado durante a última etapa do resfriamento, e durante este período parte da austenita enriquecida de carbono se transforma em martensita, apresentando influência significativa nas propriedades mecânicas [3]. Entretanto, as vantagens e desvantagens da sua presença nos aços bainíticos ainda não são bem compreendidas, principalmente os seus efeitos sobre a tenacidade $[1,7]$.

Outros elementos microligantes como $\mathrm{B}, \mathrm{Nb}, \mathrm{V}$ e Ti, podem ser adicionados para melhorar propriedades mecânicas por favorecerem a formação de precipitados e refinar o tamanho de grão [8].

Em geral, os aços bainíticos de baixo carbono mostram ser uma excelente alternativa econômica para manufatura de produtos forjados em aplicações da indústria automotiva e off-road, como em virabrequins, eixos e sistemas de direção e injeção, frequentemente fabricados com aços endurecidos por precipitação ou aços para tempera e revenimento. Isto se deve à possibilidade de uma rota de fabricação mais enxuta sem deixar de atender os requisitos de propriedades dos componentes [9].
Além da composição química e das condições de como o material foi processado, o resfriamento influencia na formação microestrutural e consequentemente nas propriedades mecânicas. As propriedades mecânicas são afetadas via microestrutura por fatores como tamanho, forma, distribuição e tipos de fases. As condições de resfriamento podem levar à formação de microestruturas mistas e complexas [10]. Diferentes tipos de bainita podem ser formadas de acordo com o resfriamento, tais como: bainita granular (GB), bainita em ripas (LB) e pacotes de ferrita bainítica (BF) [2]. É possível também que o tipo de resfriamento forme microestrutura mista com bainita de diversas morfologias, além de outras microestruturas como constituintes secundários martensita-austenita $(\mathrm{M} / \mathrm{A})$, ferrita poligonal (FP) e ferrita acicular (FA) [1].

Conhecer a resposta do material perante às condições de resfriamento é importante para a definição e planejamento da rota de fabricação dos componentes mecânicos, que leva em conta as solicitações em serviço, custos, complexidade dos processos de fabricação e histórico de falhas. Desta forma, o presente trabalho visou avaliar a influência do meio de resfriamento sobre a microestrutura do aço bainítico DIN 18MnCrSiMo6-4 a partir de uma temperatura de processamento termomecânico, a fim de gerar um de padrão de reconhecimento microestrutural via Microscopia Óptica deste aço.

Este trabalho está incorporado no escopo do projeto "Energy Efficient Manufacturing Chain for Advanced Bainitic Forging Steels Based on Thermo-Mechanical Processing", vinculado ao programa Brazilian-German Collaborative Research Initiative on Smart Connected Manufacturing (BRAGECRIM), que visa estudar a viabilidade da aplicação de aços bainíticos ao processo de forjamento e posterior resfriamento contínuo, a fim de reduzir o consumo energético na fabricação de componentes mecânicos forjados.

\section{Materiais e métodos}

O aço bainítico utilizado no presente estudo apresenta baixo teor de carbono e baixa liga. A Tabela 1 mostra a composição química do aço bainítico DIN 18MnCrSiMo6-4.

As amostras para a caracterização inicial de microestrutura e de dureza foram extraídas nos sentidos transversal e longitudinal de uma barra de $44 \mathrm{~mm}$ de diâmetro, laminada a quente e resfriada ao ar (condição de recebimento). Para análise em microscópio óptico, as amostras foram preparadas conforme procedimentos padrão de preparação metalográfica e então atacadas com Nital $2 \%$. As medições de dureza foram realizadas em um microdurômetro Vickers aplicando-se uma carga de 1000 gf durante 10 segundos em 5 pontos de cada amostra.

Tabela 1. Composição Química

\begin{tabular}{ccccccccccccc}
\hline Elemento & $\mathbf{C}$ & $\mathbf{S i}$ & $\mathbf{M n}$ & $\mathbf{S}$ & $\mathbf{N i}$ & $\mathbf{C r}$ & $\mathbf{C u}$ & $\mathbf{M o}$ & $\mathbf{A l}$ & $\mathbf{T i}$ & $\mathbf{N}$ & $\mathbf{F e}$ \\
\hline \% em massa & 0.18 & 1.19 & 1.42 & 0.015 & 0.063 & 1.17 & 0.10 & 0.27 & 0.005 & 0.004 & 0.01 & Balanço \\
\hline
\end{tabular}


Os experimentos de resfriamento foram conduzidos de tal forma a utilizar amostras com seções de um quarto de círculo obtidas da barra com volume aproximado em $6 \mathrm{~cm}^{3}$. Os resfriamentos foram divididos em duas partes. A Figura 1a e 1b mostram os ciclos térmicos aplicados na primeira e segunda parte do experimento, respectivamente, enquanto que a Figura 1c mostra o diagrama de transformação por resfriamento contínuo (CCT) do aço bainítico DIN 18MnCrSiMo6-4.

$\mathrm{Na}$ primeira parte experimental, quatro amostras foram inseridas no forno e austenitizadas a $1200^{\circ} \mathrm{C}$ durante 1 hora, e então resfriadas até temperatura ambiente em quatro diferentes meios: água, óleo, ar e em forno. A elevada temperatura de austenitização foi escolhida com base em temperaturas de processamento termomecânico. Na segunda parte experimental, foi utilizada uma metodologia similar ao tratamento térmico de austêmpera, onde uma amostra foi austenitizada a $1200^{\circ} \mathrm{C}$ durante 1 hora, e então resfriada em banho da liga metálica Zamak aquecido a $420^{\circ} \mathrm{C}$, e mantida durante 15 minutos. Posteriormente, a amostra foi retirada do banho e resfriada em água até atingir temperatura ambiente. Após os resfriamentos, ambas as amostras foram submetidas à análise da microestrutura e dureza.

\section{Resultados e discussão}

\subsection{Caracterização da microestrutura inicial}

As Figuras 2a e 2b mostram as micrografias da seção transversal na região do núcleo da barra, as quais apresentam bandas de segregação provenientes da solidificação [11] em ampliações de 200x e 500x, respectivamente. As Figuras 2c e 2d mostram a microestrutura da região de meio raio da barra em lentes de 500x e 1000x respectivamente.

A microestrutura inicial da barra de aço DIN 18MnCrSiMo6-4 é composta por ferrita poligonal e bainita granular. Segundo Wang et al. [8] e Zhou et al. [12], a bainita granular é formada por constituintes $\mathrm{M} / \mathrm{A}$ dispersos em uma matriz ferrítico-bainítica. A dureza nesta condição é de aproximadamente $325 \pm 4$ HV1.

De acordo com Morales-Rivas et al. [13], as regiões de bandeamento apresentam enriquecimento de elementos como $\mathrm{Si}, \mathrm{Cr}$ e $\mathrm{Mo}$, e empobrecimento de $\mathrm{Mn}$ quando comparado à matriz, causado pela formação de sulfeto de manganês (MnS). Além disso, relatam que não há diferença de microestrutura da matriz para as bandas de segregação no aço bainítico em que realizou seu estudo.
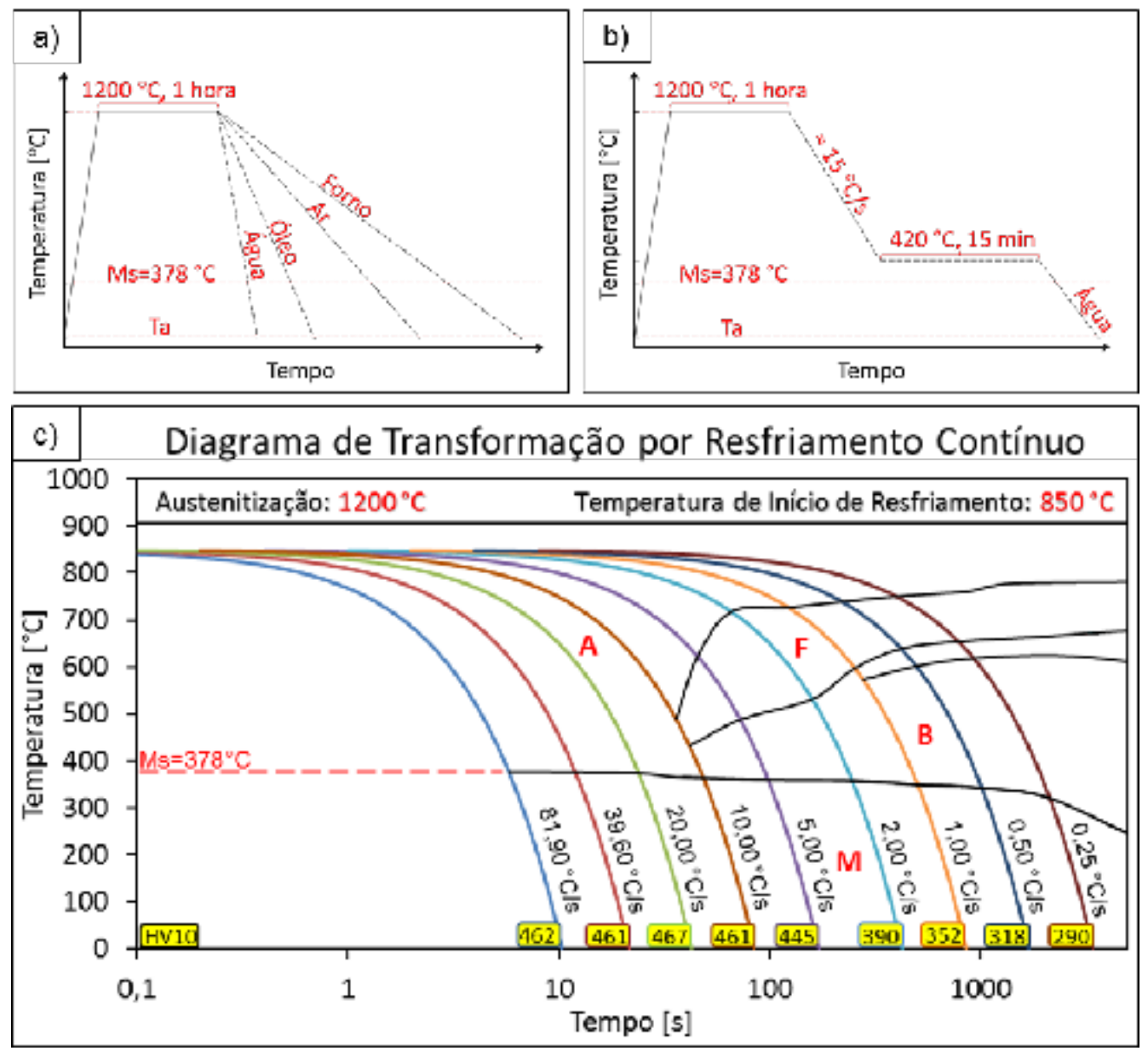

Figura 1. Ciclos Térmicos. (a) Primeira parte experimental; (b) Segunda parte experimental; (c) Diagrama de transformação por resfriamento continuo fornecido pela Steeltech, fabricante do aço. 

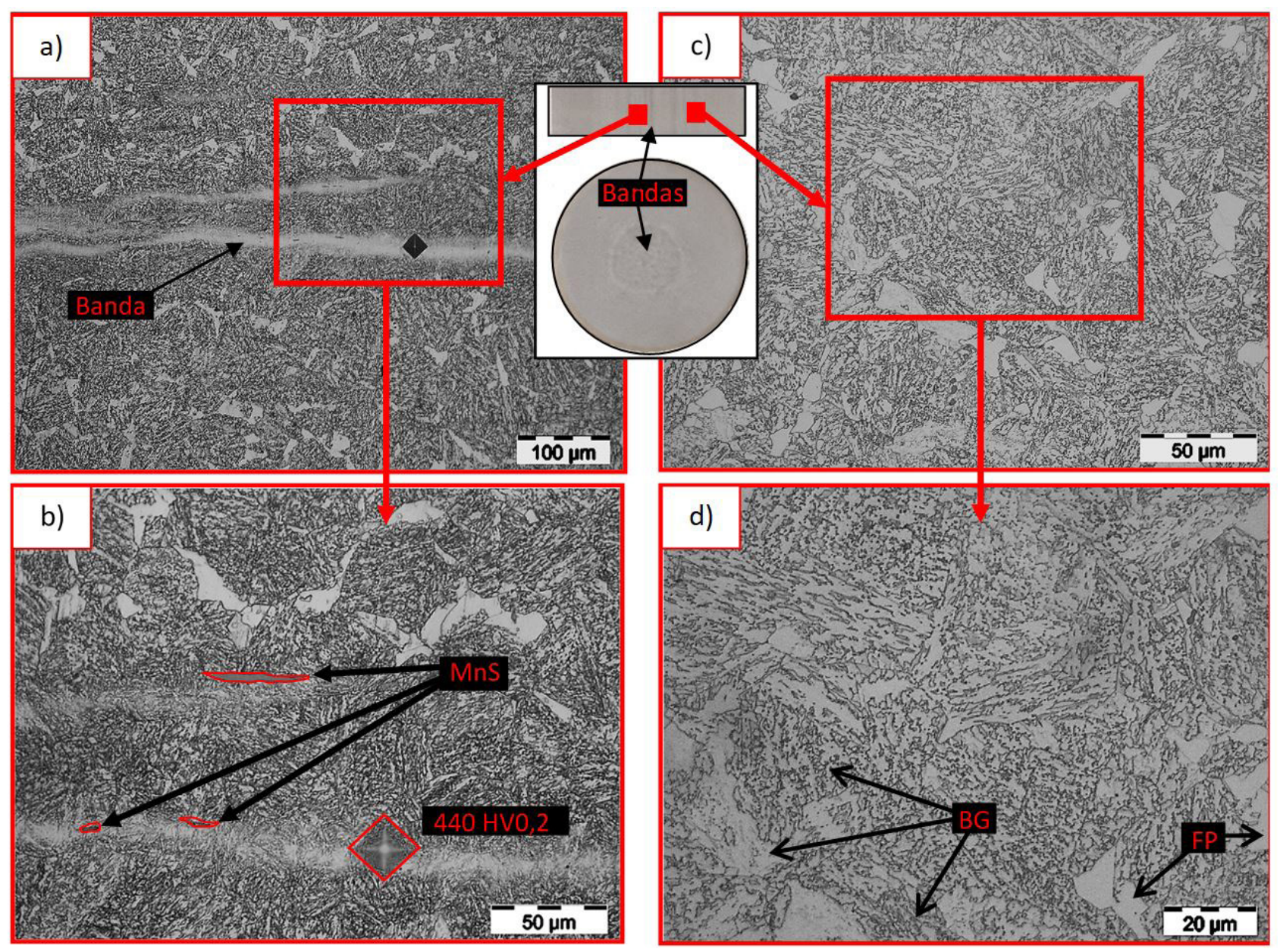

Figura 2. Análise metalográfica da barra na condição de recebimento. (a) região de núcleo em 200x; (b) região de núcleo em 500x; (c) região de meio-raio em 500x; (d) região de meio-raio em 1000x. Ataque Nital 2 \%. MnS: Sulfeto de manganês; BG: Bainita granular; FP: Ferrita poligonal; HV: Hardness Vickers.

Por outro lado, Caballero et al. [11] relatam que há presença de martensita nas bandas segregação de um aço bainítico de composição química similar ao do aço do presente estudo. A microestrutura da região do núcleo da barra do material do presente estudo apresenta inclusões de $\mathrm{MnS}$ e bandas de segregação alongados no sentido longitudinal devido à laminação. A dureza da região da banda de segregação é superior à dureza da matriz, cerca de $440 \mathrm{HV} 0,2$ ( $\approx 115 \mathrm{HV}$ maior), indicando assim como Caballero et al. [11] o aumento de dureza nestas regiões. Porém não é possível dizer se este aumento de dureza é proveniente da formação de martensita.

\subsection{Caracterização da microestrutura final}

O tamanho de grão austenítico em que se iniciou o resfriamento para ambas as condições foi medido através da amostra temperada, e apresentou diâmetro médio de $42 \pm 6 \mu \mathrm{m}$.

\subsubsection{Resfriamento em forno}

As Figuras $3 a$ e $3 b$ mostram em ampliações de 100x e 500x, respectivamente, a microestrutura formada após o resfriamento em forno a partir de $1200^{\circ} \mathrm{C}$ até $40^{\circ} \mathrm{C}$ (aproximadamente 15 horas). É possível visualizar maior formação de ferrita poligonal (regiões claras) quando comparado ao material em seu estado laminado.

O resfriamento em forno é mais lento do que o resfriamento contínuo do processo de fabricação da barra laminada, e isto faz com que o material permaneça mais tempo no campo de transformação ferrítica da curva CCT, consequentemente, apresentará maior fração de ferrita.

As regiões escuras, conforme a Figura 3c, mostram a formação de bainita granular de morfologia muito similar à bainita da condição da barra laminada (Figura 2). Mesmo em resfriamentos mais lentos, como é o caso do resfriamento em forno, não é possível visualizar por microscopia óptica, a formação de perlita. Isto se deve ao teor de Si que inibe a formação de cementita $[5,14]$. As regiões de bainita devem ter maior quantidade de $\mathrm{C}$ visto que, segundo Wang et al. [8] a 
formação de ferrita poligonal particiona carbono para austenita remanescente, e isto faz que a austenita se torne mais estável, reduzindo a temperatura final de transformação para bainita.

Devido à maior formação de ferrita poligonal, que é uma fase menos dura do que a microestrutura bainítica, a dureza após o resfriamento reduziu-se a $256 \pm 9 \mathrm{HV}$. Aços para construção mecânica de baixo carbono e baixa liga como DIN 20MnCr5, apresentam dureza abaixo de $200 \mathrm{HV}$ após o recozimento [15]. A dureza mais elevada no aço DIN 18MnCrSiMo6-4 é consequência da formação de bainita granular e ferrita poligonal ao invés de perlita e ferrita poligonal.

\subsubsection{Resfriamento ao ar}

As Figuras 4a e 4b mostram em ampliações de 200x e 500x, respectivamente, a microestrutura formada após o resfriamento ao ar a partir de $1200^{\circ} \mathrm{C}$.

É possível observar a formação de bainita granular em sua totalidade. Não é possível observar a formação de ferrita poligonal. As regiões mais claras ocorrem devido ao corte da amostra estar na mesma orientação específica do crescimento preferencial da bainita naquela região, e não devem ser confundidas com constituintes M/A ou ferrita [16].

A microestrutura formada por resfriamento ao ar apresenta diferenças da microestrutura do resfriamento

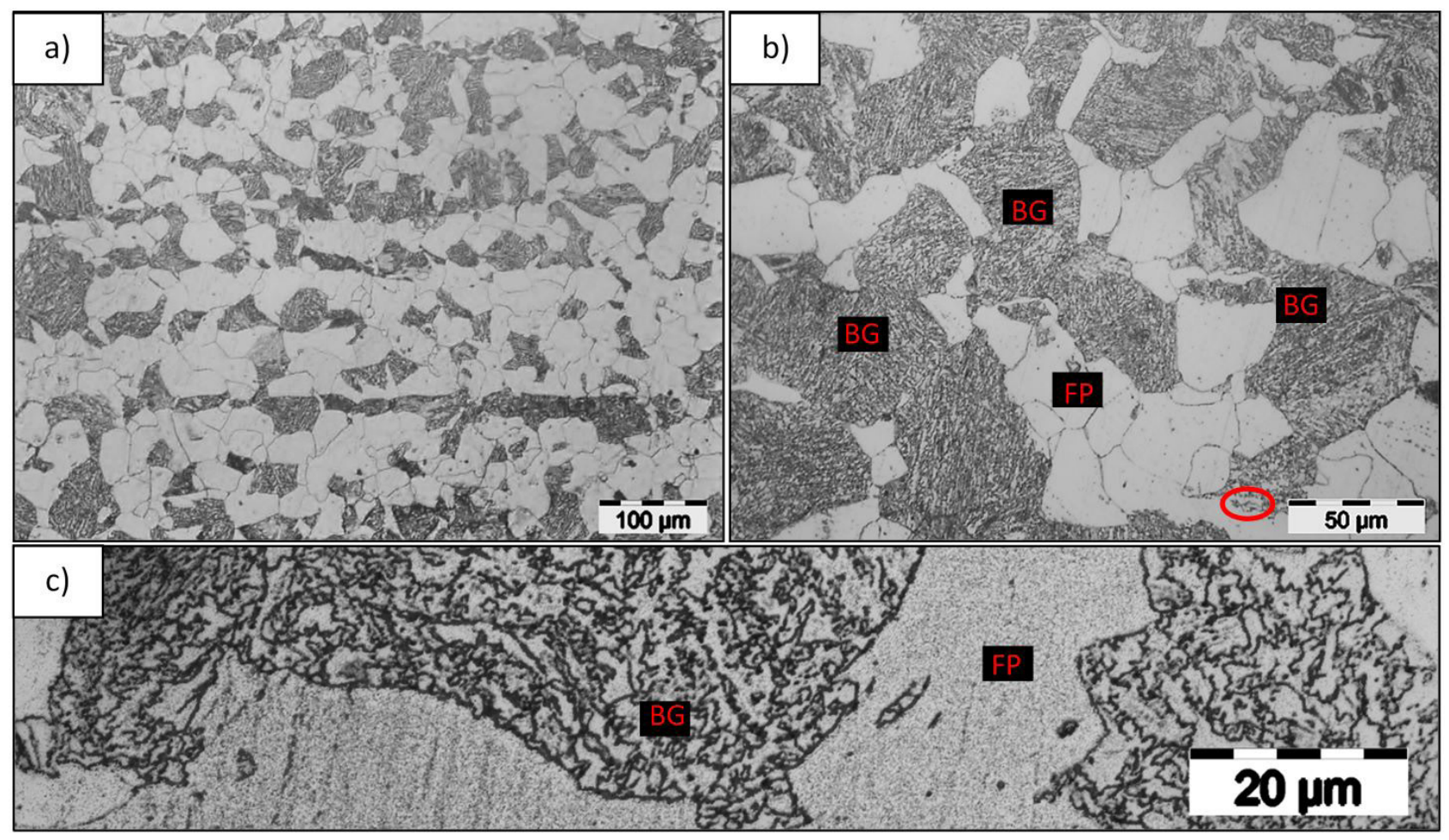

Figura 3. Resfriamento em forno. (a) 200x; (b) 500x; (c) Ampliação de 1000x da região da Figura 6b circulada. Ataque Nital 2\%. BG: Bainita granular; FP: Ferrita poligonal.
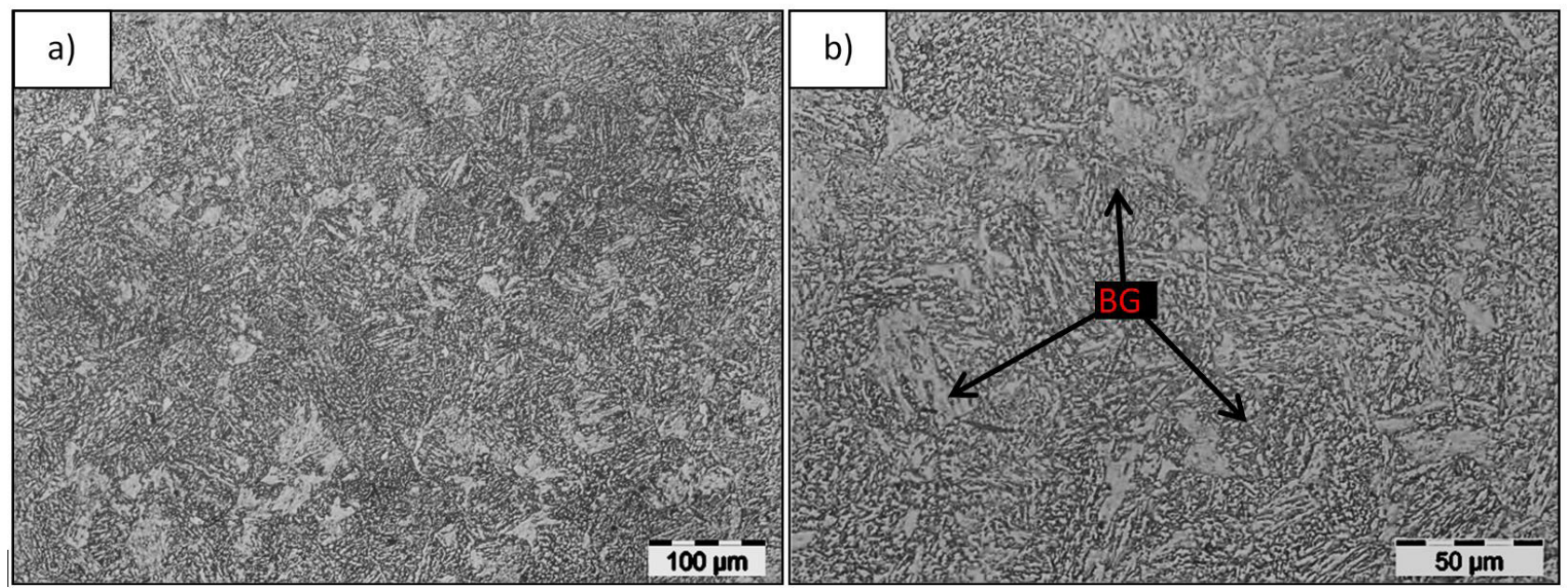

Figura 4. Resfriamento ao ar. (a) 200x; (b) 500x. Ataque Nital 2\%. BG: Bainita granular. 
contínuo após a laminação da barra. Esta diferença pode ser devido à temperatura ambiente, efeitos da deformação durante a laminação, volume de material a ser resfriado, dentre outros fatores. A dureza após este resfriamento é de $349 \pm 8 \mathrm{HV} 1$, ligeiramente maior que na condição da barra laminada, consequência da supressão de ferrita poligonal.

\subsubsection{Resfriamento em banho isotérmico}

As Figuras 5a e 5b mostram em ampliações de 200x e 500x, respectivamente, a microestrutura formada após o resfriamento das amostras em banho de Zamac aquecido à $420^{\circ} \mathrm{C}$ e mantidas por 15 minutos, com posterior resfriamento em água.

É possível observar a formação de bainita granular e bainita em ripas. Há formação de bainita em ripas devido a maior força motriz que o banho aquecido fornece durante a transformação bainítica [17].

Segundo Garcia-Mateo et al. [18] o teor de carbono influencia no tempo de transformação banítica. Conforme a concentração de carbono diminui, o tempo de transformação bainítica também diminui, ou seja, aços de baixo carbono tem menores tempos de transformação, cerca de $100 \mathrm{~s}$ para um aço com $0,2 \% \mathrm{C}$ em peso. Desta forma, o tempo de $15 \mathrm{~min}$ (900 s) em temperatura utilizado neste trabalho, foi suficiente para a transformação bainítica. Segundo Chang, por meio de medições durante a transformação isotérmica, a temperatura de transformação tem maior impacto na fração volumétrica transformada em bainita do que no tempo de transformação [19].

A dureza nesta condição de resfriamento foi de $374 \pm 10 \mathrm{HV} 1$, muito similar à dureza da microestrutura proveniente do resfriamento ao ar, visto que não ocorreu a formação de grandes frações de bainita em ripas.

\subsubsection{Resfriamento em óleo}

As Figuras 6a e 6b mostram em ampliações de 200x e 500x, respectivamente, a microestrutura formada após o resfriamento em óleo a partir de $1200{ }^{\circ} \mathrm{C}$.
O resfriamento em óleo é mais acelerado que ao ar, e isto é rápido suficiente para a formação de martensita. É possível observar a formação de pacotes de martensita em ripas (laminar), característica de aços baixo carbono [20]. A transformação da austenita ocorre a partir da divisão do grão austenítico em pacotes de martensita, os quais contém blocos subdivididos em estrutura laminar. É possível que ocorra a formação de bainita em ripas entre as ripas de martensita, porém a diferenciação por microscopia óptica é limitada. Luo et al, observaram e quantificaram por ataque químico com coloração de microestruturas, cerca de $25 \%$ de bainita em ripas misturadas aos pacotes de martensita em um aço baixo carbono e média liga temperado em óleo [21].

Em virtude da formação de martensita, a dureza desta microestrutura após o resfriamento alcançou $424 \pm 1$ HV1. Segundo Ericsson, a dureza da martensita é altamente dependente do teor de carbono presente na composição química. Aços baixo carbono e baixa liga podem ter sua microestrutura transformada inteiramente em martensita, porém, de baixa dureza. Ericsson relata ainda que teores de carbono próximos à 0,2\% em peso em aços baixa liga, podem formar até $99 \%$ de martensita e dureza máxima de 45 HRC ( $\approx 446 \mathrm{HV})$ [15].

\subsubsection{Resfriamento em água}

As Figuras 7a e 7b mostram em ampliações de 200x e 500x, respectivamente, a microestrutura martensítica formada após o resfriamento em água a partir de $1200^{\circ} \mathrm{C}$.

A dureza desta microestrutura é de $436 \pm 2$ HV1, muito similar à dureza da amostra resfriada em óleo, entretanto, a morfologia dos pacotes da microestrutura em cada condição é ligeiramente distinta. Conforme mencionado, a tempera em óleo pode formar ripas de bainita misturadas aos pacotes de martensita de acordo com a taxa de resfriamento. Nesta linha de raciocínio, na tempera em água, devido a taxas de resfriamento mais acentuadas, menores frações de bainita podem ser formadas, ou ainda, conforme relatado por Luo et al. [21], não ocorrer a formação ripas de bainita.
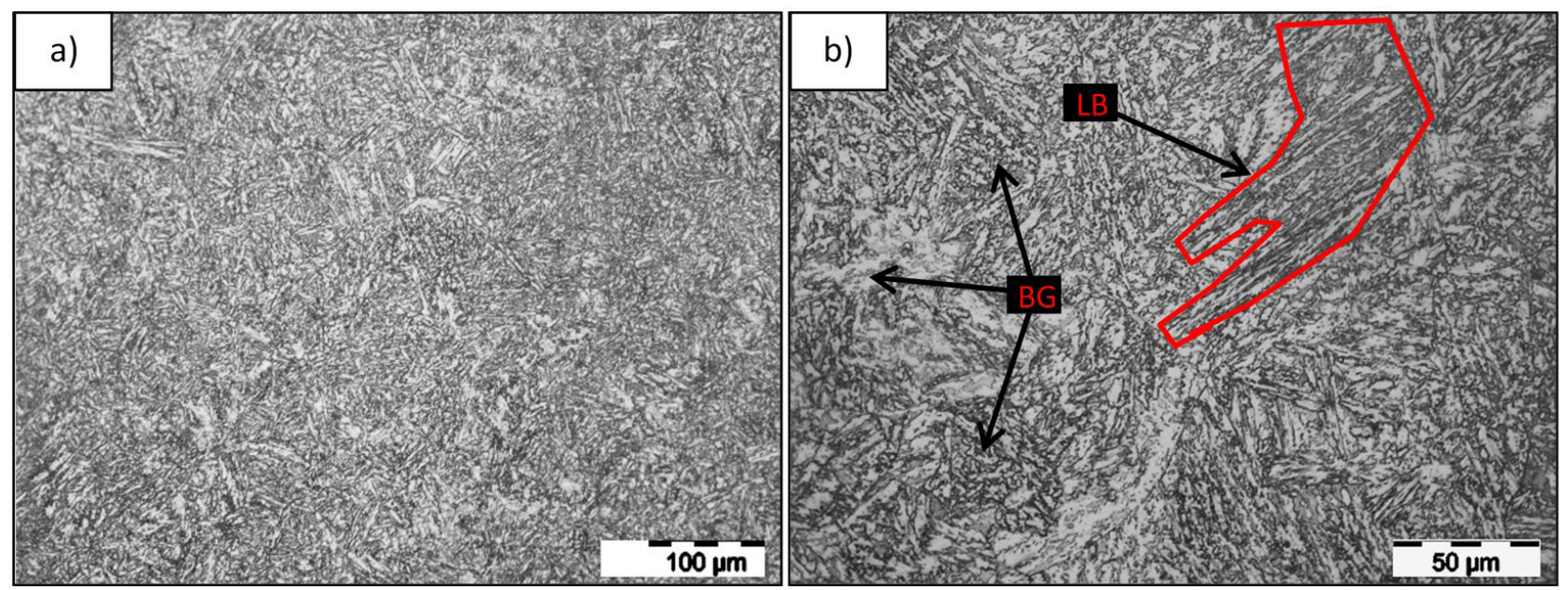

Figura 5. Resfriamento em Banho. (a) 200x; (b) 500x. Ataque Nital 2\%. BG: Bainita granular; LB: Bainita em ripas. 


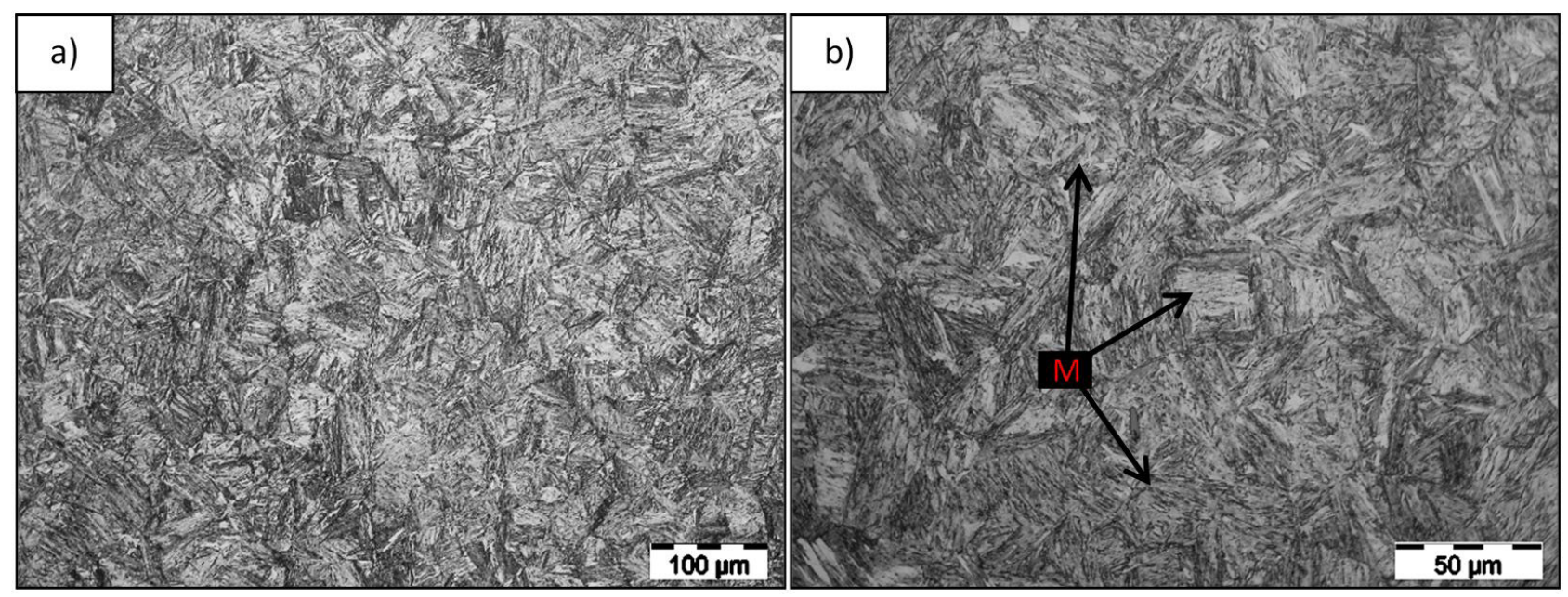

Figura 6. Resfriamento em óleo. (a) 200x; (b) 500x. Ataque Nital 2\%. M: Martensita.
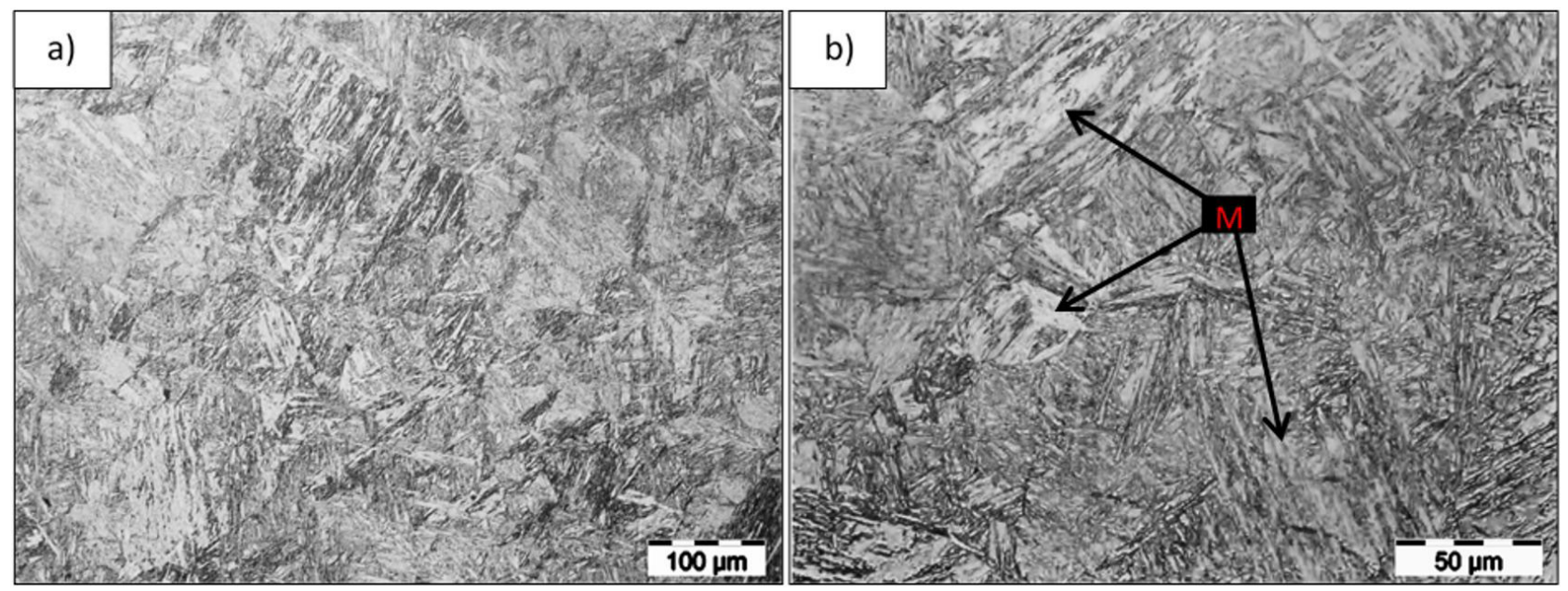

Figura 7. Resfriamento em água. (a) 200x; (b) 500x. Ataque Nital 2\%. M: Martensita.

Tabela 2. Microestruturas resultantes da microscopia óptica e suas respectivas durezas

\begin{tabular}{lcc}
\hline \multicolumn{1}{c}{ Resfriamento } & Microestrutura & Dureza (HV1) \\
\hline Condição de recebimento & $\mathrm{BG}+\mathrm{FP}$ & $325 \pm 5$ \\
Em Forno & $\mathrm{BG}+\mathrm{FP}$ & $256 \pm 9$ \\
Ao Ar & $\mathrm{BG}$ & $349 \pm 8$ \\
Em Banho Isotérmico & $\mathrm{BG}+\mathrm{LB}$ & $374 \pm 10$ \\
Em Óleo & $\mathrm{M}$ & $424 \pm 1$ \\
Em Água & $\mathrm{M}$ & $436 \pm 2$ \\
\hline
\end{tabular}

A Tabela 2 mostra em resumo a compilação das microestruturas e durezas para cada meio de resfriamento. Fica evidente a evolução da microestrutura e dureza do aço bainítico com a mudança do meio de resfriamento devido as diferentes taxas de resfriamento.

\section{Conclusão}

A aplicação da microscopia óptica foi empregada no presente estudo para avaliar a influência do resfriamento na microestrutura do aço bainítico DIN 18MnCrSiMo6-4 e assim gerar um padrão de reconhecimento microestrutural por microscopia óptica. Conclui-se que:

- Com o aumento das taxas de resfriamento há variação morfológica de tal maneira que se evita a nucleação e crescimento da ferrita poligonal, e consequentemente ocorre aumento de dureza;

- O resfriamento em forno proporciona formação de bainita granular e ferrita poligonal com maior quantidade de ferrita quando comparado à condição de recebimento, resultando em uma a dureza inferior (256 \pm 9 HV1);

- O resfriamento ao ar não apresentou a formação de ferrita poligonal e a dureza resultante (349 \pm 8 HV1) foi ligeiramente superior à dureza na condição de recebimento (325 $\pm 5 \mathrm{HV} 1)$;

- O resfriamento em banho isotérmico apresentou a formação de bainita granular com pouca formação 
de bainita em ripas, que não modificou a dureza de forma significativa (374 $\pm 10 \mathrm{HV} 1)$;

- Os resfriamentos em óleo e água apresentaram a formação de martensita em ambas condições e durezas ligeiramente distintas ( $424 \pm 1 \mathrm{HV} 1$ e 436 \pm 2 HV1, respectivamente). A martensita de baixa dureza é em decorrência do baixo teor de carbono presente no aço bainítico.

\section{Agradecimentos}

Os autores agradecem a Coordenação de Aperfeiçoamento de Pessoal de Nível Superior - Brasil (CAPES), processo $\mathrm{n}^{\mathrm{o}} 88887.142483 / 2017-00$, auxílio ${ }^{\circ} 1844 / 17$, e Conselho Nacional de Desenvolvimento Científico e Tecnológico - Brasil (CNPq), processos PQ 308773/2018-7 e 130025/2019-4, pelo apoio financeiro.

\section{Referências}

1 Lan HF, Du LX, Misra RDK. Effect of microstructural constituents on strength-toughness combination in a low carbon bainitic steel. Materials Science and Engineering A. 2014;611:194-200.

2 Wang K, Tan Z, Gao G, Gao B, Gui X, Misra RDK, et al. Microstructure-property relationship in bainitic steel: the effect of austempering. Materials Science and Engineering A. 2016;675:120-127.

3 Kyung Sung H, Ho Lee D, Yong Shin S, Lee S, Yong Yoo J, Hwang B. Effect of finish cooling temperature on microstructure and mechanical properties of high-strength bainitic steels containing $\mathrm{Cr}$, Mo, and $\mathrm{B}$. Materials Science and Engineering A. 2015;624:14-22.

4 Liang J, Zhao Z, Tang D, Ye N, Yang S, Liu W. Improved microstructural homogeneity and mechanical property of medium manganese steel with Mn segregation banding by alternating lath matrix. Materials Science and Engineering A. 2018;711:175-181.

5 Qian L, Zhou Q, Zhang F, Meng J, Zhang M, Tian Y. Microstructure and mechanical properties of a low carbon carbide-free bainitic steel co-alloyed with Al and Si. Materials \& Design. 2012;39:264-268.

6 Zhu K, Mager C, Huang M. Effect of substitution of Si by Al on the microstructure and mechanical properties of bainitic transformation-induced plasticity steels. Journal of Materials Science and Technology. 2017;33(12):14751486 .

7 Hofer C, Bliznuk V, Verdiere A, Petrov R, Winkelhofer F, Clemens H, et al. High-resolution characterization of the martensite-austenite constituent in a carbide-free bainitic steel. Materials Characterization. 2018;144:182-190.

8 Wang JP, Yang ZG, Bai BZ, Fang HS. Grain refinement and microstructural evolution of grain boundary allotriomorphic ferrite/granula bainite steel after prior austenite deformation. Materials Science and Engineering A. 2004;369:112-118.

9 Sourmail T. Bainite and superbainite in long products and forged applications. HTM Journal of Heat Treatment and Materials. 2017;72(6):371-378.

10 Zhao MC, Yang K, Shan Y. The effects of thermo-mechanical control process on microstructures and mechanical properties of a commercial pipeline steel. Materials Science and Engineering A. 2002;335:14-20.

11 Caballero FG, Chao J, Cornide J, García-Mateo C, Santofimia MJ, Capdevila C. Toughness deterioration in advanced high strength bainitic steels. Materials Science and Engineering A. 2009;525:87-95.

12 Zhou Y, Jia T, Zhang X, Liu Z, Misra RDK. Investigation on tempering of granular bainite in an offshore platform steel. Materials Science and Engineering A. 2015;626:352-361.

13 Morales-Rivas L, Roelofs H, Hasler S, Garcia-Mateo C, Caballero FG. Detailed characterization of complex banding in air-cooled bainitic steels. Journal of Mining and Metallurgy, Section B: Metallurgy. 2015;51(1):25-32.

14 Kozeschnik E, Bhadeshia HKDH. Influence of silicon on cementite precipitation in steels. Materials Science and Technology. 2008;24(3):343-347.

15 ASM Handbook Commitee. ASM Handbook. Heat Treating. Vol. 4. 10th ed. Materials Park, Ohio: ASM International; 1991.

16 Long X, Zhang F, Yang Z, Lv B. Study on microstructures and properties of carbide-free and carbide-bearing bainitic steels. Materials Science and Engineering A. 2018;715:10-16.

17 Kong X, Qiu C. Continuous cooling bainite transformation characteristics of a low carbon microalloyed steel under the simulated welding thermal cycle process. Journal of Materials Science and Technology. 2013;29(5):446-450.

18 Garcia-Mateo C, Caballero FG, Bhadeshia HKDH. Development of hard bainite. ISIJ International. 2003;43(8):1238-1243. 
19 Chang LC. Microstructures and reaction kinetics of bainite transformation in Si-rich steels. Materials Science and Engineering A. 2004;368:175-182.

20 Zhang P, Chen Y, Xiao W, Ping D, Zhao X. Twin structure of the lath martensite in low carbon steel. Progress in Natural Science: Materials International. 2016;26(2):169-172.

21 Luo Z, Shen J, Su H, Ding Y, Yang C, Zhu X. Effect of substructure on toughness of lath martensite/bainite mixed structure in low-carbon steels. Journal of Iron and Steel Research International. 2010;17(11):40-48.

Recebido em: 18 Mar. 2020

Aceito em: 16 Out. 2020 